\title{
Perception Levels of the Tribal Women on Domestic Water Sanitation Practices in Adilabad District, India
}

\author{
A. Lalitha* and R. Neela Rani
}

Department of Home Science Extension and communication management, Hyderabad, Professor Jayashankar Telangana State Agricultural University, Andhra Pradesh, India

*Corresponding author

\section{A B S T R A C T}

\begin{tabular}{|l|}
\hline Ke y w o r d s \\
Research problem, \\
$\begin{array}{l}\text { Perception, Experimental } \\
\text { research, Rebbena, } \\
\text { Thandur, Kerimeri }\end{array}$ \\
\hline Article Info \\
\hline $\begin{array}{l}\text { Accepted: } \\
\text { 04 July 2018 } \\
\text { Available Online: } \\
\text { 10 August 2018 }\end{array}$ \\
\hline
\end{tabular}

A present study was conducted on perception level of tribal women on domestic water sanitation practices. For the study, based upon the nature of the research problem and objectives of the present study, experimental research design was selected. A total of 60 tribal women from three mandals of Adilabad district were selected using random sampling technique. The district of Adilabad was selected purposively as the tribes are densely populated when compared to the other districts of the state. Tribal mandals selected for the study were Rebbena, Tandur and Kerameri. Score card was developed for data collection. Rank order and Quartile deviation were used for data analysis. The results of the study were revealed that Rank order of the perception statements showed that tribal women expressed their highly favorable perception towards the statements "Washing hands with soap before handling water and food", "Boiling of drinking water for 10 minutes" and "Washing hands with soap after defecation" and were ranked as 1, 2 and 3 respectively by the tribal women.

\section{Introduction}

Safe drinking water is human health. Water for drinking must be pure. Water quality, howsoever good at source, deteriorates during transfer in domestic containers. Various diseases like diarrhea, dysentery, cholera and jaundice are transmitted through contaminated water and poor sanitation. Two third of all illness in India is related to water borne diseases such as typhoid, diarrhea and dysentery. As usual, children and women were the worst sufferers, due to lack of safe drinking water regarding hygienic practices. Therefore, there is an urgent need to educate the tribal women regarding hygienic practices and provide safe drinking water in tribal areas. Few methods are being used at household level to make water safe for drinking in rural areas, namely, boiling and filtering through muslin cloth. Chlorine tablet is rarely used at home.

Francis et al., (2015) reported that faulty perception on water treatment, lack of knowledge about health hazards associated with drinking unsafe water, false sense of perception from locally available water, resistance to change in taste or odor of water and a lack of support from male members of 
the household were important factors impending acceptance and long term use of the intervention.

Joshi et al., (2014) in their study "Water and sanitation hygiene practices in urban slum settings" reported that all participants perceived that hands should be washed prior to handling of food. Other perceived critical times of hand washing were after defecation $(88 \%)$ and after eating $(75 \%)$ among other reasons. Almost all participants washed their hands before eating food (98\%).

$78 \%$ of the participants washed their hands because they perceived it was hygienic, and because it could prevent infection (75\%). Almost all participants (98\%) disposed their solid wastes in the community dustbins.

Bharti et al., (2013) in their study revealed that all informants perceived about importance of covered drinking water in prevention of diseases but covered drinking water was found in $96.8 \%$ of households and stored in earthen pots $(92.5 \%)$. Around two third of informants $(64.4 \%)$ did not know about importance of ladle to draw water while ladle was actually being used in less than one third $(30.5 \%)$ of households only.

Berg (2009) In their study on "Perception of health risk and averting behavior- An analysis of household water consumption in Southwest Sri Lanka" reported that a higher perceived risk induces households with and without a house connection to treat water more before drinking it, which indicates that households in our sample are aware that the action of boiling/filtering water is one type of preventing behavior against the risk of illness.

\section{Materials and Methods}

For the study, based upon the nature of the research problem and objectives of the present study, experimental research design was selected.

A total of 60 tribal women from three mandals of Adilabad district were selected using random sampling technique. The district of Adilabad was selected purposively as the tribes are densely populated when compared to the other districts of the state.

The high incidence of mortality and morbidity among tribals due to unsafe drinking water is also an important factor which led to the selection of this particular location. Tribal mandals selected for the study were Rebbena, Tandur and Kerameri.

Variables selected for the study to measure the perception level of respondents on domestic water sanitation practices, a list of eleven statements seeking different key messages were prepared. These listed items were administered to the respondents. The Score card was developed for the study.

The individual respondent was asked to state on a three point continuum highly favorable, favorable and unfavorable towards the statements, with a score of 3,2 and 1 for the responses respectively. This was collected to measure the acceptance levels of tribal women towards various information recommended practices related to effective domestic water sanitation.

Rank order was used to know the distribution pattern of the respondents according to the variables. Quartile deviation was used to identify the third and first quartile ranges in the data set of the perception of the respondents.

\section{Results and Discussion}

The results of the present study was presented below 
With regard to the statement "Collection of water from safe water sources only" majority $(70.00 \%)$ of the tribal women expressed highly favorable perception followed by favorable perception $(30.00 \%)$.

With respect to statement "Boiling of drinking water for 10 minutes" three fourth $(78.33 \%)$ of the tribal women expressed highly favorable perception followed by 21.66 per cent of them had favorable perception.

About the statement "Drinking chlorinated water" majority $(61.66 \%)$ of the tribal women had highly favorable perception while remaining 38.33 per cent of them had favorable perception. With regard to the statement "Cleaning of water container regularly" more than half $(63.33 \%)$ of the tribal women expressed highly favorable perception followed by favorable perception $(36.66 \%)$.

Regarding the statement "Use of handle donga or pot with tap for taking out water" majority $(60.00 \%)$ of the tribal women expressed highly favorable perception while forty percent of them expressed favorable perception.

With regards to the statement "Conducting the biological test once in 3 months" more than half $(56.66 \%)$ of the tribal women expressed highly favorable perception fallowed by favorable perception $(43.33 \%)$.

The statement "Use of O.R.S as first aid for diarrhea patient" was accepted by majority $(51.66 \%)$ of the tribal women followed by favorable perception (48.33\%).

It could be seen for the statement "washing hands with soap before handling water and food" a great majority $(81.66 \%)$ of the tribal women expressed highly favorable perception followed by favorable perception (18.33\%).

For the statement "Washing hands with soap after defecation" nearly three fourth of the tribal women expressed highly favorable perception followed by favorable perception (26.66\%) (Table 1).

Fig.1 Quartile deviation in perception of tribal women

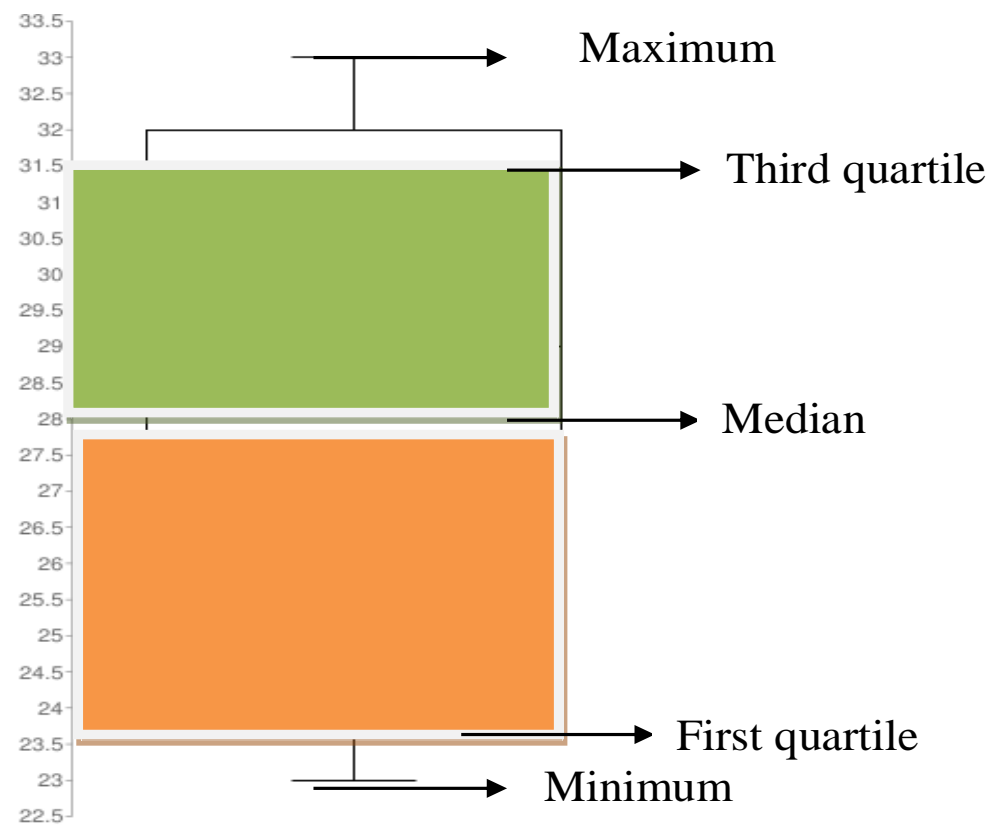




\begin{tabular}{|c|c|c|c|c|c|}
\hline & & & & & $\mathrm{N}=60$ \\
\hline S. No. & Statements & Highly favorable & Rank & Favorable & Unfavorable \\
\hline 1. & $\begin{array}{l}\text { Collection of water from } \\
\text { safe water sources only }\end{array}$ & $\begin{array}{c}42 \\
(70.00 \%)\end{array}$ & 5 & $\begin{array}{c}18 \\
(30.00 \%)\end{array}$ & - \\
\hline 2. & $\begin{array}{l}\text { Boiling of drinking water } \\
\text { for } 10 \text { minutes }\end{array}$ & $\begin{array}{c}47 \\
(78.33 \%)\end{array}$ & 2 & $\begin{array}{c}13 \\
(21.66 \%)\end{array}$ & - \\
\hline 3. & $\begin{array}{l}\text { Drinking chlorinated } \\
\text { water }\end{array}$ & $\begin{array}{c}37 \\
(61.66 \%)\end{array}$ & 7 & $\begin{array}{c}23 \\
(38.33 \%)\end{array}$ & - \\
\hline 4. & $\begin{array}{l}\text { Cleaning of water } \\
\text { container regularly }\end{array}$ & $\begin{array}{c}38 \\
(63.33 \%)\end{array}$ & 6 & $\begin{array}{c}22 \\
(36.6 \%)\end{array}$ & - \\
\hline 5. & $\begin{array}{l}\text { Use of handle donga or } \\
\text { pot with tap for taking out } \\
\text { water }\end{array}$ & $\begin{array}{c}36 \\
(60.00 \%)\end{array}$ & 8 & $\begin{array}{c}24 \\
(40.00 \%)\end{array}$ & - \\
\hline 6. & $\begin{array}{l}\text { Conducting the biological } \\
\text { test once in } 3 \text { months }\end{array}$ & $\begin{array}{c}34 \\
(56.66 \%)\end{array}$ & 9 & $\begin{array}{c}26 \\
(43.33 \%)\end{array}$ & - \\
\hline 7. & $\begin{array}{l}\text { Use of O.R.S as first aid } \\
\text { for diarrhea patient }\end{array}$ & $\begin{array}{c}31 \\
(51.66 \%)\end{array}$ & 10 & $\begin{array}{c}29 \\
(48.33 \%)\end{array}$ & - \\
\hline 8. & $\begin{array}{l}\text { Washing hands with soap } \\
\text { before handling water and } \\
\text { food }\end{array}$ & $\begin{array}{c}49 \\
(81.66 \%)\end{array}$ & 1 & $\begin{array}{c}11 \\
(18.33 \%)\end{array}$ & - \\
\hline 9. & $\begin{array}{l}\text { Washing hands with soap } \\
\text { after defecation }\end{array}$ & $\begin{array}{c}44 \\
(73.33 \%)\end{array}$ & 3 & $\begin{array}{c}16 \\
(26.66 \%)\end{array}$ & - \\
\hline 10. & $\begin{array}{l}\text { Diverting waste water to } \\
\text { backyard garden }\end{array}$ & $\begin{array}{c}43 \\
(71.66 \%)\end{array}$ & 4 & $\begin{array}{c}10 \\
(16.66 \%)\end{array}$ & $\begin{array}{c}7 \\
(11.66 \%)\end{array}$ \\
\hline 11. & $\begin{array}{l}\text { Construction of soakage } \\
\text { pit }\end{array}$ & $\begin{array}{c}27 \\
(45.00 \%)\end{array}$ & 11 & $\begin{array}{c}22 \\
(36.66 \%)\end{array}$ & $\begin{array}{c}11 \\
(18.33 \%)\end{array}$ \\
\hline
\end{tabular}

For the statement "Diverting waste water to backyard garden" it is clear that majority $(71.66 \%)$ of the tribal women expressed highly favorable perception followed by favorable perception $(16.66 \%)$ and unfavorable perception (11.66\%).

The statement "Construction of soakage pit" was highly perceived by 45.00 percent of the tribal women as highly favorable while 36.66 per cent of them felt favorable perception followed by unfavorable perception (18.33\%).

On the whole, the statements "Washing hands with soap before handling water and food", "Boiling of drinking water for 10 minutes" and "Washing hands with soap after defecation" were perceived highly favorable and were ranked as 1,2 and 3 respectively by the tribal women. The probable reason for their ranking might be due to the fact that the said three statements were crucial recommended practices for reducing the incidents of mortality and morbidity caused by water borne diseases.

The other reason might be that in the multimedia module the key messages on the said statements were showed through illustrations with animation repeatedly. This might be resulted due to the change in their perception made them convinced and accepted the practice which lead to highly favorable perception. 
Quartile Range in perception on domestic water sanitation

The quartile range is the most obvious measure of dispersion and is the difference between the lowest and highest values in a dataset.

Quartile Range in perception of tribal women on domestic water sanitation practices

The quartile deviation of the tribal women's perception towards the practices of domestic water sanitation revealed that the sixty tribal women rated their perception favorable to highly favorable with 33 as obtained maximum score and 23 as minimum score against the actual maximum score 33 and 11 score as minimum. It was very clear from the Figure 1 . That $25 \%$ of the tribal women fell under Q1 (first quartile) range with a score value of less than or equal to 25 . The median value 29 is scored by $50 \%$ of the respondents. While 75 percent of the respondents fell under Q3 (third quartile) range with a score value of less than or equal to 32 .

From the study, it was concluded that Rank order of the perception statements showed that tribal women expressed their highly favorable perception towards the statements "Washing hands with soap before handling water and food", "Boiling of drinking water for 10 minutes" and "Washing hands with soap after defecation" and were ranked as 1,2 and 3 respectively by the tribal women. Twenty five percent of the tribal women fell under Q1 (first quartile) range with a score value of less than or equal to 25 . The median value 29 is scored by $50 \%$ of the respondents, while 75 percent of the respondents fell under Q3 (third quartile) range with a score value of less than or equal to 32 .

Majority of the respondents increased their knowledge and changed their perception on water sanitation after exposure to multimedia module.

\section{References}

Berg, C.V.D. 2009. Perception of health risk and averting behavior- An analysis of household water consumption in Southwest Sri Lanka World Bank report.

Bharti, M. M., Kumar, V., Verma, R., Chawla, S. and Sachdeva, S. 2013. Knowledge Attitude and Practices Regarding Water Handling and Water Quality Assessment in a Rural Block of Haryana. International Journal of Basic and Applied Medical Sciences. 3 (2).243-247

Francis, M.R., Nagarajan, G., Sarkar, R., Mohan, V.R., Kang. G and Vinohar Balraj. V. 2015 Perception of drinking water safety and factors influencing acceptance and sustainability of a water quality intervention in rural southern India. Journal of Bio med central public health.2-9

Joshi, A., Prasad, S., Kasav, J., Segan, M. and Singh, A. 2014. Water and Sanitation Hygiene Knowledge Attitude Practice in Urban Slum Settings. Global Journal of Health Science. 6 (2): 23-34.

\section{How to cite this article:}

Lalitha, A. and Neela Rani, R. 2018. Perception Levels of the Tribal Women on Domestic Water Sanitation Practices in Adilabad District, India. Int.J.Curr.Microbiol.App.Sci. 7(08): 187-191. doi: https://doi.org/10.20546/ijcmas.2018.708.025 